\title{
The Relevance of Rehabilitation Centers in our Communities
}

\author{
Archibald Danquah-Amoah ${ }^{1}$,Dr. Amit Alexander Charan ${ }^{2}$ \\ ${ }^{1} \mathrm{PhD}$ Research scholars, Department of Molecular and Cellular Engineering.(Jacob Institute of biotechnology, and bioengineering). Sam \\ Higginbottom University of Agriculture Technology \& Sciences (Shuats). Nani, Allahabad (UP).India \\ ${ }^{2}$ Assistant Professor, Department of Molecular and Cellular Engineering.(Jacob Institute of biotechnology, and bioengineering). Sam \\ Higginbottom University of Agriculture Technology \& Sciences (Shuats). Nani, Allahabad (UP).India
}

\begin{abstract}
Rehabilitation describes specialized healthcare dedicated to improving, maintaining or restoring physical strength, cognition and mobility with maximized results. Typically, rehabilitation helps people gain greater independence after illness, injury or surgery. Rehabilitation of people with disabilities is a process aimed at enabling them to reach and maintain their optimal physical, sensory, intellectual, psychological and social functional level. It involves a team of physicians, specially trained therapists, and nurses, as well as psychologists, nutritionists, biomedical engineers, and chaplains forms a circle of care centered around the patient and their family. There many types of rehabilitation centers some specialize in helping patients with a specific drug addiction, aged, handicap or disable people and others offer a broader range of drug addiction services. Some rehab (rehabilitation) facilities are even gender or age specific, as this often helps patients feel more comfortable in the rehab (rehabilitation) setting. A rehabilitation center is a facility that seeks to help individuals recover from a variety of ailments, some physical and others caused by substance abuse or mental illness. Rehabilitation center are not only for treating drug addicts but are also for the treatments depressions cause by the scio-economical problems such low income, unemployment which a times might result in mental disorders. The availability of rehabilitation centers have the capacity to improve many lives, by solving of many problems in terms of quality of human health in the communities and the society at large.
\end{abstract}

Keywords: rehabilitation, center, improving, restoring, and disability

\section{Introduction}

Rehabilitation is the processes of helping an individual achieve the highest level of function, independence, and quality of life possible. Rehabilitation does not reverse or undo the damage caused by disease or trauma, but rather helps restore the individual to optimal health, functioning, and well-being (Lakeland Health, 2017). In 2014, Marianjoy rehabilitation hospital said that the practice of rehabilitation medicine is based on a holistic and comprehensive approach to medical care for individuals who have experienced an impairment resulting from an injury, disease process or developmental disorder. The rehabilitation process uses an interdisciplinary team of health care professionals to help a person to reach their fullest physical, psychological, social, vocational, a vocational, and educational potential consistent with his or her goals and life plans. Residential rehabilitation - rehab for short - describes a drug or alcohol treatment programme that is provided in a residential setting. Rehabs are usually abstinence-based and provide an intense programme of support and care aimed at people who have difficulty becoming drug free in the community (Public Health England, 2017). Rehabilitation describes specialized healthcare dedicated to improving, maintaining or restoring physical strength, cognition and mobility with maximized results. Typically, rehabilitation helps people gain greater independence after illness, injury or surgery. It always delivered by a diverse team of experts, rehabilitation blends many specialties for the best treatment plan, such as physical therapy for increased strength and mobility, Occupational therapy for improved everyday living skills, and Speech and language therapy for improved communication. WHO in 2017 mention that rehabilitation of people with disabilities is a process aimed at enabling them to reach and maintain their optimal physical, sensory, intellectual, psychological and social functional levels. Rehabilitation provides disabled people with the tools they need to attain independence and self-determination.

\section{Integrated Approach Rehabilitation}

Integrated care team of physicians, specially trained therapists, and nurses, as well as psychologists, nutritionists, and chaplains forms a circle of care centered around the patient and their family. Interdisciplinary health care team evaluates not only the patient's present disability, but the impact the disability has on the whole person mind, body, and spirit. The rehabilitation process begins by setting goals with the patient and their family. These goals help to shape a treatment plan designed to improve the patient's physical, perceptual, and communication abilities, while developing skills to compensate for any permanent disability. The health care team includes physiatrists, rehabilitation nurses, physical therapists, occupational therapists, speech pathologists, psychologists, and case manager

Areas Covered In Rehabilitation Programs May Include The Following:

1) Self-care skills, including activities of daily living (ADLs) these are feeding, grooming, bathing, dressing, toileting, and sexual function.

2) Physical care these are nutritional needs, medication, and skin care

3) Family support these includes assistance with adapting to lifestyle changes, financial concerns, and discharge planning

4) Psychological counseling these includes identifying problems and solutions with thinking, behavioral, and emotional issues 


\section{International Journal of Science and Research (IJSR) \\ ISSN (Online): 2319-7064}

Index Copernicus Value (2015): 78.96 | Impact Factor (2015): 6.391

5) Pain management these includes medications and alternative methods of managing pain.

6) Vocational training these includes work-related skills.

7) Socialization skills these includes interacting with others at home and within the community

8) Cognitive skills these includes memory, concentration, judgment, problem solving, and organizational skills

9) Communication skills these includes speech, writing, and alternative methods of communication

10) Respiratory care this includes ventilator care, if needed; breathing treatments and exercises to promote lung function.

11) Mobility skills these includes walking, transfers, and self-propelling a wheelchair.

12) Education these includes patient and family education and training about the condition, medical care, and adaptive techniques.

\section{Traditional Rehabilitation Models Or Newer, More Locally-Based Models Approach}

Traditional models of rehab often involve the person having a complete break from their current circumstances and staying at a centre that is away from their home and drugusing environment. Newer models of residential treatment are emerging across the globe, which include supported housing provision linked to structured treatment and other local services. Some rehabs provide residential treatment in stages. Although this is not universally the case, stages of rehab are broadly mapped as follows: Stage 1: First stage usually corresponds to short-stay rehabilitative programmes or the initial stages (up to 12 weeks) of long-stay rehabilitative programmes, focusing on intensive therapeutic interventions and the immediate responses to becoming drug free Stage 2: Second stage usually corresponds to the later stages (more than 12 weeks) of long-stay rehabilitative programmes, focusing on the development of life skills, reintegration through education, training or employmentfocused needs; the skills required to sustain a drug-free lifestyle while still receiving intensive support from the programme Stage 3: Third stage is offered by some organizations and usually corresponds to independent living and supported housing with some support and mentoring maintained with the main rehab.

Philosophies approaches provided by traditional model rehabilitation to help the individual

Therapeutic Community; in a therapeutic community, staff and clients participate together as members of a social and learning community. The service may have a hierarchical structure which residents work through and in which each stage has a different pattern of activity, together with growing freedom and responsibilities. Time will be spent in therapeutic group work, one-to-one key work sessions, developing practical skills and interests, education and training. The therapeutic community models have been adapted over the years and made shorter and more flexible. The intensive nature of their approach to individual psychology still means that they tend to be among the longer programmes (6 - 12 months).

Christian Philosophy/Faith-based; Faith-based services have religious staff and may or may not require residents to share their faith or participate in faith-related activities These activities will include the time studying religious texts and the lessons to be learned from them, in discussion and in prayer.

Eclectic or Integrated; These are programmes which do not adhere to a particular philosophy and use a range of different methods and interventions focused on meeting the needs of individual residents.

Cognitive behavioural therapy (CBT) and social learning; these are programmes that include psychological treatments such as CBT, in which actions are believed to influence future behaviour. The V Program for Domestic Violence people are the psycho-education class. Psychoeducation is a treatment that instructs people about their problem, how to treat their problem, and how to recognize the signs of reoccurrence so the offender can go to treatment before the problem comes back. Psycho-education programs include cognitive behavioral techniques and motivational (Miceli ,2009).

Personal and skills development; the programme in a service operating a personal or skills development model may focus less on psychological therapeutic interventions and more on the practical skills and knowledge needed to get by in the wider community. They may be closely linked with local education or employment training providers and residents will spend much of their time in structured programmes of educational classes, training activities and group work. There may also be opportunities for work experience.

\section{The usage of rehabilitation centers}

A rehabilitation center will offer one or more of these therapies on premises. A rehabilitation center may be outpatient only. Some hospitals offer in-patient rehabilitation. There are many different types of drug rehab facilities. There many types of rehabilitation centers some specialize in helping patients with a specific drug addiction; others offer a broader range of drug addiction services. Some rehab facilities are even gender- or age-specific, as this often helps patients feel more comfortable in the rehab setting. Inpatient and outpatient rehab facilities are also available. Doctors in rehab or rehabilitation centers may administer medications to patients to assist them in their recovery. A patient may take medication to control mental or physical drug abuse triggers. This medical treatment can be short term or long term, depending on the patient's circumstances and needs. A rehabilitation center is a facility that seeks to help individuals recover from a variety of ailments, some physical and others caused by substance abuse or mental illness. Some centers offer residential areas, where those being treated will stay overnight. Others are strictly outpatient facilities. Many will specialize in either physical rehabilitation, or substance abuse rehabilitation. A physical rehabilitation center offering residential services often doubles as a nursing home, though depending on the setup, the patients may be kept separately. These homes are especially good for those who require a substantial amount of physical rehabilitation. Often, for those who live alone after surgery, a rehab or rehabilitation center may be the only option until they regain their mobility. This allows 


\section{International Journal of Science and Research (IJSR) \\ ISSN (Online): 2319-7064}

Index Copernicus Value (2015): 78.96 | Impact Factor (2015): 6.391

them to have someone else focus on the daily duties, such as cooking and cleaning while they are able to work on physical and occupational therapy. This type of rehabilitation center is often a cheaper option than a hospital setting. It also offers an intermediate level of care between the hospital and home environment. Further, there are usually full time occupational and physical therapists on staff. These individuals will often work with patients on a daily basis to help in the recovery process. This daily attention may provide the quickest path to recovery (Ken, 2017). Rehabilitation is programs that help the individual to stop whatever addiction they have, or at least give them the education to help them stop. Alcohol treatment for an alcoholic, anger management treatment for someone whom has assaultive behavior, drug treatment for drug addicts and sexual treatment for a criminal that has committed a sexual crime. They also have classes for educate the individual so that he or she could get out of such behavior (Linda and Brumley 2012). Hussey (2008) said that it is important to keep patient away from the surrounding or public where the addiction began while selecting rehabilitation center. An outpatient handling program is sufficient, in early period of addiction. Those patients whose history with alcohol addiction requires an inpatient management program wherein patient's improvement is monitored all the day and is supervised. This type of treatment is done in a housing surrounding or in hospital that offers control like hospital. Well maintained rehabilitation centers are found in all main cities. Rehab center not only works to make sure that the patient does not go back to addiction but also works toward the treatment of the patient. They bring back the confidence and faith of the addict's that they have lost. This type of patient come out as a confident individual with renewed energy and is prepared to face years.

\section{Discussion}

Nowadays, rehabilitation for alcohol abuse is gaining huge popularity. Alcohol rehabilitation helps a patient's physical as well as mental health through different approaches, medicines and support. Professional counselors and physicians suggest the right mix of treatment for individual patient who is fighting with the problem of alcohol abuse. Alcoholism is more of a psychological illness and it needs proper care and treatment. The goal of any kind of rehabilitation is to improve the condition of lives of affected people who have realized their problems. In recent times, rehab is available for almost all kinds of physical as well as mental problems. Be it lung or heart problems, spinal disorders, cancer, depression, anxiety or alcoholism, rehabilitation treatments are available for all. Rehabilitation treatments are given to stabilize the uneven mental condition of patients by cultivating good thoughts and engaging their mind in some productive work. Using therapies and treatments, efforts are put to regain the lost mental ability to fight with any kind of trauma in their lives. Therefore the need for establishment of more rehab or rehabilitation centers in our communities that we live. Ken in 2017 also said that some types of rehabilitation centers are mostly cheaper option than hospital setting. Rehabilitation center are not only for treating drug addicts but are also for the treatments depressions cause by the Scio-economical problems such low income, unemployment which a times might result in mental disorders. If these people are not catered for it will really affect the communities by making the communities poorer and much unsaved to live. The rehab or rehabilitation center also serves as a home for the aged. These aged people most of them don't have families. Through the rehab center they are care for in terms of food, health, and recreational activities are available for them. The rehabilitation centers also serves as a training centers for the handicap persons living in the communities. At the center most of them are skillful trained in various vocations to help the handicap or disable person make a living by earning some money through his or her vocations. This help to prevent them to be begging for money and doing other thing that are bad to the society. Even the center also serves as a recreational grounds for them due to the provision of some specially made amusement facilities for the disable or handicap people.

\section{Conclusion}

The provision and availability of rehabilitation centers have the capacity to improve many lives, by solving of many problems in terms of quality of human health in the communities and the society at large. Rehabilitation treatments are given to stabilize the uneven mental condition of patients by cultivating good thoughts and engaging their mind in some productive work. It helps the person to develop and utilize their full potential through a process of learning and support from the environment. Rehabilitation complements psychiatric treatment through a holistic approach by guiding persons with mental illness to be treated and reintegration of the individual back into their own community

\section{References}

[1] Andrews, D. A., Bonta, J., and Hoge, R. D. (1990). Classification for effective rehabilitation: Rediscovering psychology. Criminal justice and Behavior, 17(1), 19-52.

[2] Carter, R., and Lubinsky, J. (2015). Rehabilitation ResearchE-Book: Principles and Applications. Elsevier Health Sciences.

[3] Dawkins, M (2017). HealthSouth. Rehabilitation hospital of Sarasota

[4] Hussey, R (2008). Meaning and Importance of Rehabilitation Center. Health articles Journal

[5] Jezernik, S., Colombo, G., Keller, T., Frueh, H., and Morari, M. (2003). Robotic orthosis lokomat: A rehabilitation and research tool. Neuromodulation: Technology at the neural interface, 6(2), 108-115.

[6] Ken B (2017).wiseGeek.

[7] Lakeland Health (2017) Napier Avenue St. Joseph, Michigan 49085

[8] Linda and Brumley,N (2012) Prisoner Rehabilitation. pp 2

[9] Marianjoy rehabilitation hospita (2014)l, Roosevelt Road Wheaton

[10] Miceli, V (2009).Analyzing the Effectiveness of Rehabilitation Programs.pp4-5.

[11] Public Health England, (2017).

[12] Spreng, R. A., Harrell, G. D., and Mackoy, R. D. (1995). Service recovery: impact on satisfaction and intentions. Journal of Services Marketing, 9(1), 15-23.

[13] World heaith organization (2017).Health topics .rehabilitation.

\section{Volume 6 Issue 7, July 2017 www.ijsr.net}

